\title{
The contribution of action research in the construction of scientific knowledge in Brazilian Production Engineering
}

\author{
Daniela Gibertoni $^{\mathrm{a} *}$, Targino de Araújo Filho ${ }^{\mathrm{b} * *}$, Nilton Luiz Menegon ${ }^{\mathrm{b} * * *}$ \\ aFaculdade de Tecnologia de Taquaritinga, Taquaritinga, SP, Brasil \\ bUniversidade Federal de São Carlos, São Carlos, SP, Brasil \\ *daniela.gibertoni@fatectq.edu.br, **targino@ufscar.br, ***menegon@dep.ufscar.br
}

\begin{abstract}
The main subject of this article is the action research and it has as general objective to describe the construction of knowledge in this field from the uses that Brazilian Production Engineering makes of it, aiming to recognize its contributions, potentials and limits. To achieve this goal, a literature review was carried out for a subsequent contrast with the national academic researches that use action research and show its uses. Identified these similarities, a documentary research was carried out in academic papers published in the National Meeting of Production Engineering (ENEGEP) - from 1996 to 2010. The content analysis was the strategy used for data analysis and NVivo ${ }^{\circledR}$ software was used for its treatment. As a conclusion of the research, it can be stated that the use of action research in the Brazilian Production Engineering distances itself from epistemic precepts associated with it. The results of the action are more highlighted than the reflection on the mechanisms that produced it.
\end{abstract}

Keywords

Action research. Research methodology. Production engineering.

\section{Introduction}

Action research is a widespread research methodology, used worldwide in different areas. Its strategies of acting combined with the objectives of research in a given area can bring along very interesting particular results. Thus, it is considered feasible to bring the historical aspect that permeates the main topic of this article: action research (AR).

Although its origin is attributed to John Dewey and John Collier (El Andaloussi, 2004; Eden \& Huxham, 2000; Dick et al., 2009), the term AR is frequently attributed by many authors (Susman \& Evered, 1978; Baskerville, 1999; Westbrook, 1995) to Kurt Lewin (1890-1947), a German psychologist who became a naturalized North American. His early work, in the mid-1940s, was one of the first applications of knowledge in the social sciences involving a researcher in the actual situation. By this means, there is an origin landmark in the history regarding $A R$, a period when a type of research differentiated from the natural or positivist research was strengthened. There is a substantial change of the researcher's role as a mere observer of the process into a transforming agent of the experienced situation.

To a large extent, a profusion of terminology arose because AR began as a unified approach to social research and it has been fragmented throughout its history. To Reason \& McArdle (2003), AR usually involves the creation of spaces in which participants engage together in cycles of action and critical reflection. However, this basic process has been designed into different ways in different types of AR when in practice.

In this regard, AR was being built as it was investigated, explored. This maturity work of AR has been developed around the world, bringing along some differences, including its own nomenclature and characteristics. All this was linked to the fact that the application object when put into practice, that is, according to the application area of AR, it brings some 
other differences which need to be better explored, such as in Production Engineering (PE).

According to Thiollent (2009), AR has become consolidated in an effective way over the years, and it can be applied in different areas such as IT, education, social science, health, engineering and others. The author also points out that the educational aspect of AR is more present and explored than its organizational aspect, thus constituting a good reason to deepen and advance research on the subject of AR in the organizational area. Another relevant aspect is that lately, in the academic area, there has been a significant growth of researches carried out through AR, but not on AR, greatly in articles published in ENEGEP. The academic community has shown concern about the application of correct uses of the methods in the PE area, when publishing a book with this theme, having a special chapter dedicated to AR (Turrioni \& Mello, 2010).

Although the method of AR in the area is currently discussed more emphatically, the arguments chosen to justify the application of AR are very often contradictory, and they mix assumptions derived from theoretical references, which are simply incompatible. Actually, these data lead us to a question: is its use a reflection of just a fad or are researchers looking for a kind of research to bring differentiated results from the traditional or positivist one?

The present article is justified by the relevance of the theme for the current era: the research methods used in PE, in particular AR, and by the perspective of theoretical reflection on the sciences with a participatory approach for the development of future researches.

In international terms, there are many publications on AR that need to be researched and analyzed in depth so it is known how AR is in the international scientific community, since there are a lot of academic papers available on the internet, in books and journals. In the national literature, there is not a compilation of these publications on the convergences and divergences when it comes to how Brazilian researchers in PE make use of AR.

Therefore, the purpose of this article is to analyze the knowledge construction in the field of AR from the uses that the PE makes of it. For this purpose, a qualitative research was conducted through documentary analysis (Godoy, 1995). The data obtained were described and Bardin (2011) content analysis was carried out. NVivo ${ }^{\circledR}$ 9 of QSR International software was used for data processing, seeking to obtain the results of analysis of the articles of the National Meeting of Production Engineering (ENEGEP), from 1996 to 2010.

According to Franco (2005), if someone chooses to work with AR, he certainly has the conviction that research and action can and must go together when the change of practice is intended. However, the direction, the meaning and the intentionality of this transformation will be the axis of the characterization of AR approach. The main characteristics that unify AR are presented in this article, as well as the research methodology, results and conclusions.

\section{The main characteristics of action research}

Through a literature review, the following items have been identified as major research-action features (those that were firmly highlighted by several authors): research and action, theory and practice, participation and the role of the researcher. The cyclical process on which AR is based to the development of research is also presented. It is important to emphasize that the available literature on research methodology and AR are derived mostly from the Social Sciences. Thus, the authors studied in this review are part of this area of knowledge. Other authors here presented bring contributions to the improvement of the use of AR in organizations. Table 1 shows briefly the main features of AR discussed in this article.

Table 1. The main characteristics of action research.

\begin{tabular}{|c|c|c|}
\hline Characteristics & Meaning & Striking terms \\
\hline Research and action & $\begin{array}{l}\text { Contribute and expand scientific knowledge } \\
\text { Solve problems and promote improvement in the organization } \\
\text { or community }\end{array}$ & $\begin{array}{l}\text { Collective action } \\
\text { Intervention }\end{array}$ \\
\hline Theory and practice & $\begin{array}{l}\text { It is fundamentally change and must be conducted in real time } \\
\text { The theory is planned to produce teachings open to } \\
\text { generalization }\end{array}$ & $\begin{array}{l}\text { Change } \\
\text { Transformation } \\
\text { Knowledge } \\
\text { Intervention } \\
\end{array}$ \\
\hline $\begin{array}{l}\text { Researcher's participation } \\
\text { and role }\end{array}$ & $\begin{array}{l}\text { Action researchers work actively to make it happen } \\
\text { He is a participant in the implementation of a system } \\
\text { He facilitates dialogue and promote reflective analysis among } \\
\text { participants }\end{array}$ & $\begin{array}{l}\text { Cooperation } \\
\text { Interaction among the researcher and the other } \\
\text { participants } \\
\text { Communication } \\
\text { Ethic }\end{array}$ \\
\hline Cyclical process & $\begin{array}{l}\text { Spiral of self-reflexive cycles } \\
\text { Diagnosis of the situation } \\
\text { Action planning } \\
\text { Writing of final results }\end{array}$ & $\begin{array}{l}\text { Learning } \\
\text { Self-critical reflection }\end{array}$ \\
\hline
\end{tabular}




\subsection{Research and action}

It is important to point out that the PE has certain characteristics that distinguish it from other engineerings. It can be stated that the difference is in its interdisciplinary aspect, in the inclusion of human systems as well as in the use of knowledge of Social Sciences in the list of its actions. This fact significantly increases the complexity of the issues addressed by the area, and consequently the methods adopted by professionals and researchers.

In AR, the action is not a mere everyday action, but one that is designed to clarify or solve a problem of life, society, education (Morin, 2004) and organization (Coughlan \& Coghlan, 2002).

In AR there is also the concern to involve two focuses: solve problems and contribute to science (Coughlan \& Coghlan, 2002; Dionne, 2007). For the authors, AR is research in the action and research on the action, thus not postulating distinction between theory and action. To corroborate the above, Huxham \& Vangen (2003) and Thiollent (2011), state that AR is the gathering of the search and the action itself and the deliberate involvement of the researcher in changing the situations being analyzed. In the PE, since it is interdisciplinary and deals with complex problems, the action of the researcher in the field should be based on a more comprehensive view possible of the problem to be treated, so that most of the factors involved are considered in its formulation and understanding. Due to these characteristics, PE is fertile ground for the application of various research approaches (including systemic approach) to solve its problems.

To Reason \& Bradbury (2001) this feature of $A R$ is called democracy and participation, where the action without reflection and without understanding is blind, as well as the theory without action is useless. Democratic and participatory construction is fundamental to work with AR. AR is only possible with, for and by the people and communities, ideally involving all interested parties (Reason \& Bradbury, 2001, p. 2).

As highlighted by Thiollent (2011, p. 97), “[...] for an action to be achievable, the subjective will of some individuals is not enough. The proposed action has to meet the requirements of the situation."

Still according to the same author, in terms of organizational context, the considered action often aims to solve seemingly more technical problems, for example, to introduce a new technology or unblock the flow of information within the organization.

Seen in these terms, it can be stated that the action will never be an individual one. It must be collective, effective, and enticing. Enticing because the action cannot be entirely planned (problems, causes, hypotheses, experimentation, evaluation). Since AR is concerned with the process, this action becomes an act of intervention. A concern we must have in mind is that the action which is qualified as research should leave room for the process of awareness, reflection, analysis, correction, verification and generation of knowledge.

In PE, when the action researcher identifies the object of study, he should proceed to present the this problem to the organization and discuss the ideas through the formation of working groups, but mainly to record all actions carried out (either by video, voice recording, journals). The accuracy of how data are treated and recorded (in meetings, interviews, questionnaires) is what really contributes for the results to be achieved.

As Desroche (1981, p. 20) points out, “[...] it is not solely a research on the action or for the action, but a survey in action [...]", for it occurs in people's real life, either within organizations, schools, or communities.

\subsection{Theory and practice}

In what way can intervention take place? What kind of change can the practice of AR cause?

AR and intervention are not mutually exclusive (Dubost \& Levy, 2002), they qualify the way the working device is built and put into practice, through which researcher (s) collaborate, also called action researchers and authors, and others who, according to the situation and theoretical framework, can be called practical, customers, partners, actors, subjects, individuals, participants or co-researchers.

AR is fundamentally a change: AR is applied to understanding, planning and implementing change in companies and organizations (Coughlan \& Coghlan, 2002; Baskerville, 1999; Westbrook, 1995; Thiollent, 2011). Since $A R$ is essentially about change, knowledge and skill are necessary in dynamic organizations. Another aspect pointed out by the same authors is that AR should be conducted in real time: it is considered a "living" case study.

AR requires the development of the general theory of value to be disseminated in a manner to arouse the interest of a wider audience than that totally involved in the action and / or the research itself (Eden \& Huxham, 2000).

Still according to the perspective of Eden \& Huxham (2000), the complete process of AR involves a series of interconnected cycles, in which the writing of the results in the final stages of a research project is an important aspect of the exploration and development 
of theory, which combines the processes of explaining the pre-understanding and the methodical reflection to formally explore and develop the theory.

The theoretical use of AR to Dubost (1987) is from the beginning, planned to produce teachings open to generalization, to guide further action or show principles or laws.

It is important to emphasize that the primary purpose of $A R$ is mainly investigative, within a process of interaction between researchers and the interested audience, to generate possible solutions to the problems identified. According to Liu (1997), AR is not limited to solving the practical problems of users, it must not be confused with a simple consulting technique, since the ambition that is associated with it also consists of advancing fundamental knowledge.

In the work of Gustavsen (2003), abundant material which discusses the relation between theory and practice can be found. The author states that AR has always existed in a field of tension between theory and practice and concludes that to learn through practice, research must develop social relationships, both internally within the research community and in relation to other actors. The new production of knowledge is above all an activity social network and research must not be left out of this process and remain as isolated individuals looking at the world from the outside and far away. As a historical factor, nothing better than to rescue Lewin's own phrase: “[...] there isn't anything more practical than good theory [...]" (Lewin, 1951, p. 169).

An important aspect to be made clear regards AR goals, which can be seen through the relation between the research objectives and action objectives, as Thiollent (2011, p. 24) points out:

a) a practical objective: to contribute to the best solution to the problem considered central in the research, with survey of solutions and their corresponding proposal of actions in order to assist the actor (participant) in his transforming activity of the situation. It must be seen realistically, that is, without exaggeration in the definition of attainable solutions since not all problems have short term solutions;

b) knowledge objective: to obtain information that would be difficult to reach through other procedures, increasing the knowledge of certain situations (claims, action skills).

There must be a constant balance between the two objectives, however, daily demands of practice often limit the time devoted to knowledge (Thiollent, 2011). To conclude this reasoning, when it comes to the application and development of AR, the researcher can emphasize one of the following three aspects: problem solving, awareness or knowledge production.
To Thiollent (2011), AR is often able to achieve only one or another of these aspects.

It is reasonable to affirm that there is no real AR without the occurrence of intervention within the problem and that this intervention will promote changes collectively, either to the environment as a whole or for the individual in this context.

Specifically in the Brazilian PE, the cultural phenomenon of the structures of organizations has to be considered so that the interventions can take place; in other words, when the researcher proposes to conduct AR, he turns out to be exposed, since he goes to the organization (or he is already a member) to negotiate this intervention. 1t is necessary for the organizations to be open and willing for this type of research, and this is one important aspect. Another aspect is related to the researcher lack of preparation for this research, for as stated by Thiollent (2009), one aspect that deserves attention is the maturity of the researcher to conduct AR because cooperative participation is fundamental (item 2.3).

\subsection{The researcher's participation and the role}

One of the aspects discussed by several authors around the world when it comes to AR is related to the types of participation. But what is participation in AR? ls participation cooperation? ls participation collaboration?

Participation is a process to be generated. The process begins with participatory intent and continues along the construction of participatory processes in an activity within the limits set by the participants and the conditions [...] (Thiollent, 2009, p. 12).

To Morin (2004, p. 67) “[...] participation requires personal engagement, openness to human activity without relation of dependence, where dialogue prevails in relations of cooperation or collaboration."

In the view of Desroche (2006), cooperation is referred to as much more demanding than participation or simple collaboration because it requires a greater degree of commitment and reciprocity among the actors involved. AR may acquire a cooperative dimension which seems more complex and far superior to mere participation operating in the more practiced participatory research (Thiollent, 2009, p. 142).

Coughlan \& Coghlan (2002) claim that action researchers do action: action researchers are not simply observing events, they are actively working to make it happen. In this sense, the authors state that $A R$ is interactive, since it requires cooperation among researchers and customers, and continuous 
adjusting to new information and new events. Therefore, AR demands total involvement of the researcher in an attempt to change the organization (Eden \& Huxham, 2000).

One of the major focuses of AR is the emphasis on the researcher's role (Westbrook, 1995). Thus, an action researcher is a participant in the performance of a system, and at the same time, he aims to evaluate certain technical intervention. Seen in these terms, the action researcher is not an independent observer, but becomes a participant, and the changing process becomes the object of research.

In many situations, the researcher's role in $A R$ is used primarily to facilitate dialogue and to promote reflective analysis among participants, to provide them with periodic reports, and to write a final report when the involvement of the researcher has ended. Since AR is carried out in real world circumstances, and it involves closing and opening communication among the people involved, the action researchers should pay close attention to ethical considerations while managing their work.

From the interrelationship between researchers (authors) and actors in the process of AR, associated with a dialogue space, results in the construction of knowledge to which it is necessary the understanding of the cultural dimension, differences in languages, social attitudes, perceptions and interpretations. Morin (2004, p. 57) bolsters Desroche's ideas when stating that "[...] a research in which the research authors and the social actors are mutually implicated: the actors in the research and the authors in action."

This means that the so-called AR projects require both the authors and the actors to play participatory roles on both sides, the actors and the authors. This happens in such a way that one "enters" the other's space, making this change substantially more than participatory, but cooperative in the sense of living action and reflecting upon it to find the best deal for a given situation.

Therefore, for research to be called AR, it is essential that it is cooperative, since it is the one that actually engages people in the research project aiming to find solutions and answers to their problems. In these terms, it is important to emphasize that in the PE field, the role of the researcher is also crucial and must be founded on the reciprocity of the acts, i.e., at some point in the research he acts as an author, at some point he acts as an actor, cooperating with those involved for the construction of new knowledge. Thus, he is not only the observer of facts, but is present in all phases of the research, cooperating for the results to be obtained from all the involved ones. Something that often get researchers confused about is the fact that just being in the organization (and thinking of participation) already defines the research as AR, when in fact, it is necessary to be together until the final moment of implementation of actions, check the results and apply corrections. This concept of the action researcher's role should be the same in any area of science.

\subsection{The cyclic process}

The cyclical process of AR is not fully standardized, because depending on the social situation or the organizational framework in which it is applied, the procedures and the ordering of steps may vary (Thiollent, 2009, p. 3).

In this context, both in national and international literature, one can find similar models for the cyclical process of AR.

Susman \& Evered (1978), in an article at that time, described in detail a crisis in organizational sciences, since conventional methods and techniques would bring less useful answers to solve practical problems within organizations. These authors, based on the theory previously presented by Lewin, increased the goals of contribution to the practice related to people, as well as the goals of the social sciences. They also contributed to develop self-help skills of people facing problems. In other words, AR can be seen as a cyclical process with five steps (Figure 1):

1) Diagnosis to identify a problem in the organization;

2) Action planning, considering the alternative actions to solve the problem;

3) Execution of actions, by selecting a script of action;

4) Evaluation of the action consequences;

5) Specific learning and identification of experience teachings, with return to the starting point to evidence generalizable knowledge acquired about the problem.

The infrastructure within the client system and the researcher action maintains and regulates some or all of these phases. This perspective is also accepted by O’Brien (1998), Coughlan \& Coghlan (2002) and Thiollent (2009), highlighting points that are milestones of AR, such as the systemic approach to equate the work social problems and to plan new forms of organization.

More than a cyclical process, Thiollent (2011) presents very important steps for conducting an AR project, from its conception to its organization. These steps are: exploratory phase, research theme, the lining of problems, place of theory, hypotheses, 


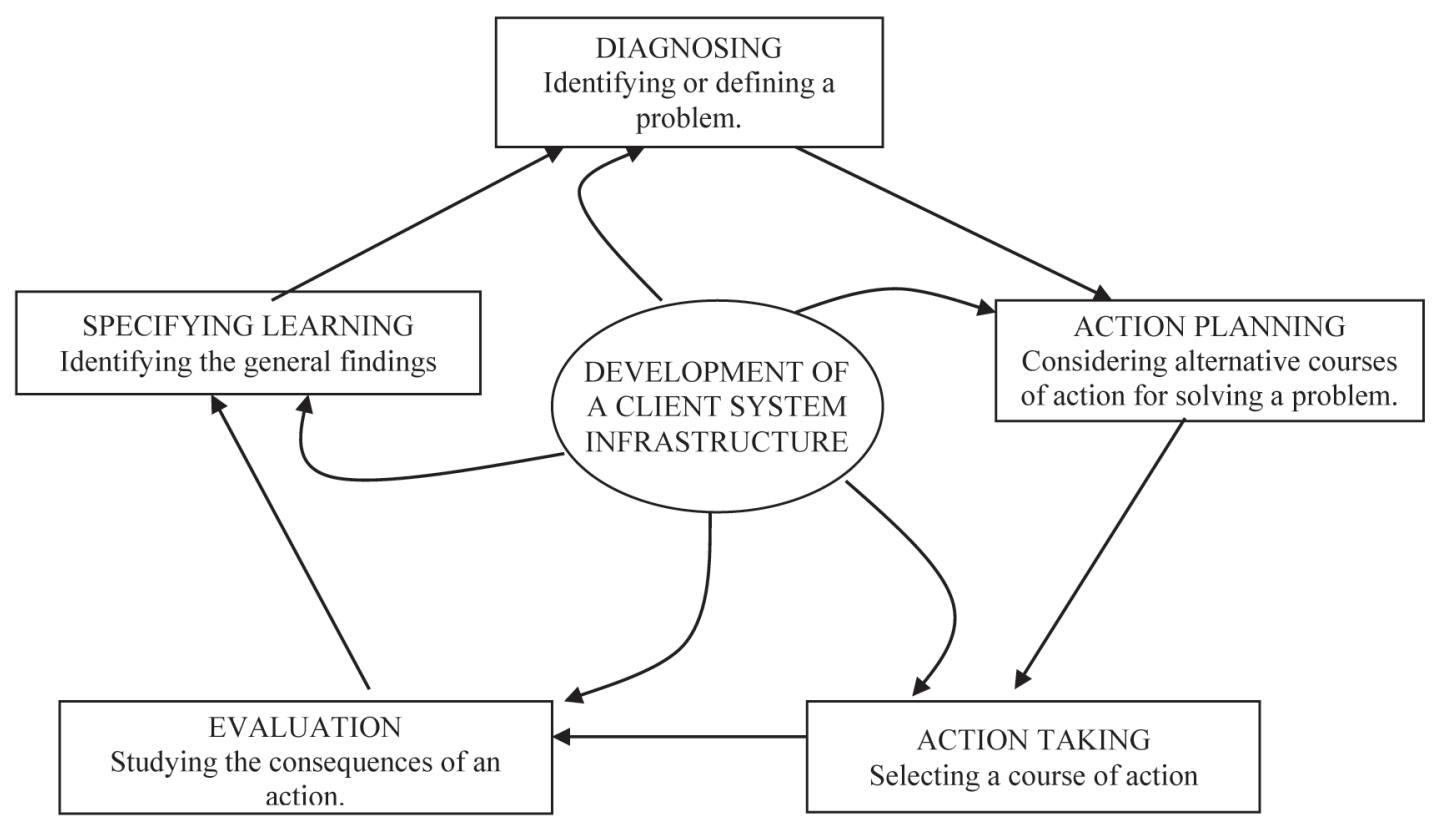

Figure 1. The cyclical process of action research. Source: Susman \& Evered (1978, p. 588).

seminar, observation field, sampling and qualitative representation, data collection, learning, formal / informal knowledge, action plan, dissemination of results.

According to Morin (2004), AR is integral and systemic, and it presents the stages of a research plan elaboration. These are:

a) Clearly identify the main needs of the group: the most important is to set the overall goal of research;

b) Properly understand the purpose of the project: it should allow changes in the order of knowledge based on the actions;

c) Sketch and illustrate the essential steps of the project: to estimate types of meetings, dates and places;

d) Determine the duration of the project: it is important to determine from the beginning the time allotted for the project;

e) Precisely define the roles of participants: it is necessary to establish a principle of equality concerning the rights of speaking and listening;

f) Assign the tasks: to enable researchers-actors to assign themselves tasks to be completed; and

g) Conclude an agreement or an open contract: speak the same language and share the roles and tasks, especially at the beginning.

Turrioni \& Mello (2010) also present a research protocol to conduct AR, however, Morin's research plan (Morin, 2004) is the most suitable to be applied in the PE, since it brings more direct and practical steps to conducting AR. The model that most closely matches the practice of PE is the one by Susman \& Evered (1978), for there is a constant concern with the construction of new knowledge, allowing researchers to innovate in the productive processes of organizations, since there is an evaluation process after the planning and execution of action.

\section{Research methodology}

A qualitative research was carried out, involving the method of content analysis, which derives from social communication and is widely applied in the social sciences.

To Bardin (2011), the main purpose of content analysis can be summarized in handling the messages, both its content and the expression of that content, to highlight indicators that allow inferring another reality different from the one of the message.

The same author also states that a content analysis is a research technique used to make valid and replicable data inferences, within their contexts. The analyzed data can be viewed based on different perspectives. The author points out that the meanings of the messages are not necessarily the same for everyonnodese (the idea of subjectivity of interpretation is implicit). "By inferring (logically deducing), the analyst takes advantage of the treatment of the messages handled [...]" (Bardin, 2011, p. 45).

The organization of the content analysis starts with three key stages (Bardin, 2011): 1) the pre-analysis; 2) the material exploration and 3) the interpretation (treatment) of results. For this research, we used NVivo ${ }^{\circledR}$ software, which brings in its conception these three stages proposed by Bardin. This is what follows. 


\subsection{Content analysis through $N V_{i v o}{ }^{\circledast} 9$ software}

For the database of articles, a search for the term AR was made, in the period from 1996 to 2010, on the website of the Brazilian Association of Production Engineering - ABEPRO (Associação Brasileira de Engenharia de Produção, 2013). This database was composed of 191 items, from approximately 10,300 articles published by the event in the period of 15 years.

By this time, the basis for research was ready. The next step was to start the use of NVivo ${ }^{\circledR}$ software, version 9. Initially, the project was structured in the software database. Then, there was the process of data coding and analysis, and as a last step, information to compose the topic related to the research results was extracted. Each stage of the process contains a sequence of activities, as shown in Figure 2. These activities were planned, considering the objectives of the article and the type of information to be analyzed. The activities performed at each stage are presented below.
Stage 1 - Research structuring in the Nvivo ${ }^{\circledR} 9$ environment

The first step in NVivo ${ }^{\circledR} 9$ software was creating the project, which was named ENEGEP with nvp extension. To load the data, i.e., for the import of 191 files, subfolders were created corresponding to the year of publication. Before inserting the articles in the base, a pre-reading or fluctuating reading of the 191 articles was done, specially the items: abstract, method or methodology and conclusion or final considerations.

Step 2 - Data coding and analysis in the NVivo ${ }^{\circledR}$ 9 environment

Whenever a piece of text is coded in $\mathrm{NVivo}^{\circledR} 9$, a reference to this fragment is stored in one or more nodes, at the researcher's discretion and according to the theoretical framework adopted for content analysis. Nodes represent previously defined or created during the review process themes or categories of analysis. In this study, ten categories and six subcategories were created and implemented. Categories and subcategories built in the software are based on research's dimensions, which can be seen in the Table 2 .

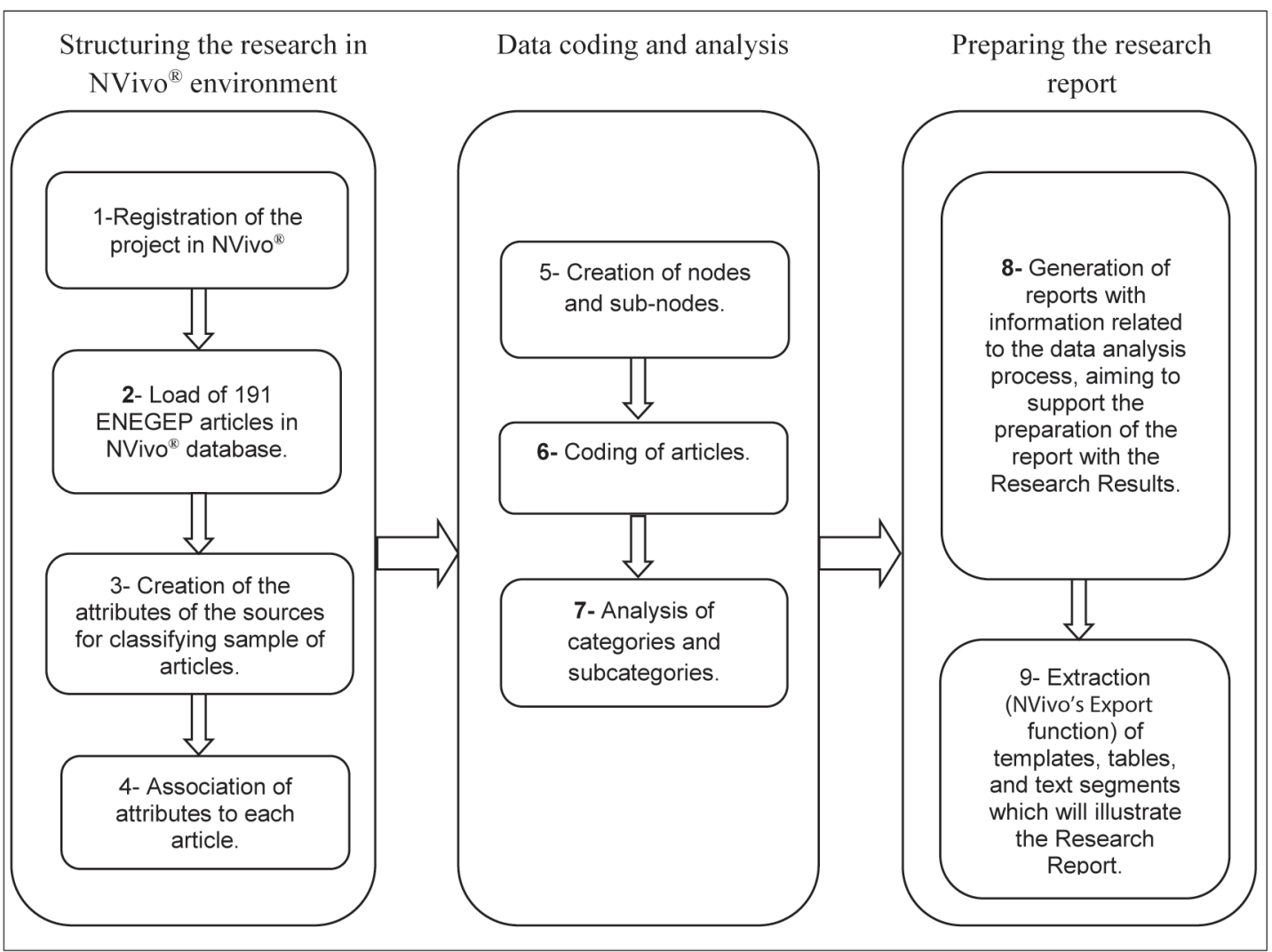

Figure 2. The process performed for data analysis of the articles of ENEGEP. Source: Elaborated by the author. 
Table 2. Research dimensions with their meanings.

\begin{tabular}{|c|c|c|}
\hline Dimension/Node & Definition & Sub-nodes \\
\hline $\begin{array}{l}\text { 1-Motivation to use action } \\
\text { research. }\end{array}$ & $\begin{array}{l}\text { 1dentify the justification given by the authors } \\
\text { when they choose to use action research }\end{array}$ & $\begin{array}{l}\text { 1. Work at the company where research was done } \\
\text { 2. Participation of the researcher } \\
\text { 3. Participation of all actors involved in action research } \\
\text { process } \\
\text { 4- Solutions in the real situation }\end{array}$ \\
\hline 2-Declaration of methodology use & $\begin{array}{l}\text { ldentify what the researcher declares to use as } \\
\text { research methodology in his article }\end{array}$ & 1. Case study; Case study and action research \\
\hline 3-Objectives of work & $\begin{array}{l}\text { 1dentify the objectives of research in order to } \\
\text { compare them to the results later on }\end{array}$ & \\
\hline 4-Objectives of action research & $\begin{array}{l}\text { 1dentify the explicit objectives action research } \\
\text { has in the article }\end{array}$ & \\
\hline 5-Results & $\begin{array}{l}\text { When coded at the root, the results regard the } \\
\text { practical ones, i.e. those specifically for the } \\
\text { results of the application concerned; when } \\
\text { there was a declaration of knowledge and / or } \\
\text { difficulties to use action research, they were } \\
\text { coded specifically in these sub-nodes }\end{array}$ & $\begin{array}{l}\text { 1. Knowledge generated from the use of the action } \\
\text { research } \\
\text { 2. Declaration of difficulties due to the use of action } \\
\text { research }\end{array}$ \\
\hline 6-Author's comments & $\begin{array}{l}\text { Present comments pointed out by researchers } \\
\text { throughout the article }\end{array}$ & \\
\hline 7-Team & $\begin{array}{l}\text { 1dentify the team(s) that worked to carry out } \\
\text { the action research }\end{array}$ & \\
\hline 8-Action research stages & $\begin{array}{l}\text { ldentify the explicit declaration of the action } \\
\text { research development stages }\end{array}$ & \\
\hline $\begin{array}{l}\text { 9-Limitations to carry out action } \\
\text { research }\end{array}$ & $\begin{array}{l}\text { Present the stated limitations for using action } \\
\text { research }\end{array}$ & \\
\hline 10-Suggestions for future actions & $\begin{array}{l}\text { The author's declaration concerning future } \\
\text { possibilities of improvements for future } \\
\text { researches }\end{array}$ & \\
\hline
\end{tabular}

Source: elaborated by the author.

These categories were defined aiming to answer the following research questions: What motivated researchers to use AR? What knowledge is generated in this research? Was it different due to the use of AR? Did they report difficulties? These questions were helpful during the process of data analysis.

\section{Step 3 - Preparation of the research report}

NVivo ${ }^{\circledR}$ provides resources to facilitate the work of the researcher, when preparing the research report. Virtually all formats of output can be exported, either to Word or Excel files.

During the preparation of a qualitative research report, it is usual to illustrate the results with excerpts from documents. Thus, the choice of these excerpts or fragments is facilitated by the software, from the moment you make use of consultations to the nodes or functionalities that allow to export the texts form the nodes to Word files.

\section{Data analysis}

\subsection{Motivation to use action research}

A research question that emerged from the analysis process was, "what are the reasons that lead researchers to choose AR?" To answer this question, the coding was done in the node (category) 'motivation to use AR'. During the coding process, a need to further specify the types of motivation found as well as the authors' foundation was observed. Thus, the following sub-nodes were built: "participation of all actors', 'participation of the researcher', 'solutions in real situations' and 'work at the company where the research is done'. The first two sub-nodes were created as a result of 397 (three hundred ninety-seven) times the word 'participation' appears in the articles analyzed, and also based on the reading done to properly code the node. After the analysis, it was found that the node 'participation of all actors' was the most common, in 47 (forty-seven) articles, as shown in the Table 3.

However, when performing the coding process of this node with its respective sub-nodes, it was also found the recurrent presence of the same quotation as justification for the use of AR. Twenty-seven (27) articles brought the following quotation:

Action research is a type of social research with empirical basis that is designed and carried out in close association with an action or solution of a collective problem and in which researchers and the participants who represent the situation or problem are involved in a cooperative or participatory way. (Thiollent, 2011, p. 20). 
Table 3. Relation of the node Motivation to use AR.

\begin{tabular}{lc}
\multicolumn{1}{c}{ Nodes and sub-nodes } & $\begin{array}{c}\text { Quantity of codified } \\
\text { sources }\end{array}$ \\
\hline Motivation to use AR. & 20 \\
- Participation of all actors & 47 \\
- Participation of the researcher & 38 \\
- Solutions in real situations & 44 \\
- Work at the company where the & 8 \\
research is done & \\
\hline Source: Elaborated by the author.
\end{tabular}

The strong use of this quotation without any other argument or basis for the use of AR characterizes a weak argument, i.e. the article's author just quoted it without even including a previous or subsequent paragraph to explain the relevance of such quotation in that context and research. This shows a kind of usage based on participation, but without having an exact idea of what type of participation that AR defends and supports.

\subsubsection{Participation of all actors}

This sub-node 'participation of all actors', was created to code passages of the articles which stated exactly who was responsible for what in the research project, thus defining the roles of each actor and author on possible actions that should be performed.

In other cases, it can be found that the justification presented is exactly consistent with the theory of $\mathrm{AR}$, namely the participation of all, cooperatively, in problematic situations for solving practical problems, having a learning process that leads to knowledge as the main "backdrop". Here is a quotation that reflects this highlighted point of convergence.

In other words, action research is an appropriate methodological procedure for research in participatory situations, that is, in which participants perform not only data collection, but also collaborate in their own decision-making process, reflect and improve their own work and connect reflection and action. (Oliveira et al., 2008).

One way or another, what can be observed is that the term participation causes a certain fascination in researchers, since there is another sub-node specially to emphasize that the justification for the choice of $A R$ is based only on the researcher's participation.

\subsubsection{Participation of the researcher}

When coding and analyzing the sub-node 'participation of the researcher', the theme and its variations were found, just as the theory of AR emphasizes: intervention, interventionist, intervenor.
In this context, another issue came to the attention of this researcher: when the author of the article claims he makes use of action research, isn't he also including the participation of the other company members in such a way that this information becomes subjective in the coding process? Because of this issue, some re-readings directly in the texts were carried out, and it could be detected that the emphasis on the participation of the researcher is actually the largest and the only one, since it was not possible to identify it even implicitly through the node 'working team'. In other words, the results of the sub-node 'participation of the researcher' were confronted with the node 'working team'. From this comparison, only five articles that explicitly spoke of the working team in the respective sub-node were identified, and therefore, reported the intervention process.

\subsubsection{Solutions in real situations}

This sub-node was created due to the recurrent justifications found in the articles for the development of research in practical environments. Thus, because of its practical and interventionist nature, AR turns out to be an excellent choice for the researcher in his search for the truth.

Certain fusion of arguments can be noticed to justify why AR is adopted. For example, Cota Junior \& Cheng (2006) wrote "As we sought to solve practical problems and enhance transformations, AR was chosen as the research strategy". This idea reinforces the practical application of AR upon which engineers rely for its implementation.

\subsubsection{Work at the company where the research is done}

The sub-node 'work in the company where the research is done' was the least coded compared to previous ones. There is an emphasis, here, on the term "participation" as the greatest motivation to use AR. This is because the authors show an understanding of $A R$ as a method where the researcher must participate in the research, however, he has no clarification and/or enough knowledge to distinguish mere participation from that cooperative participation on the lines of $\mathrm{AR}$, as discussed in section 2.3 of this article.

\subsection{Declarations of the phases for implementation of action research}

The node 'AR phases of implementation' was created to obtain the results concerning the declarations of AR phases. Also, the appropriate coding was done 
for each article where it was explicitly stated how the research process was carried out.

Thus, one aspect observed is the fact that there are declarations of the phases according to the subarea studied in the articles, in such a way that these standards are obeyed when conducting the practical process. For example, if the article studies quality, then the authors can make use of QFD method or the PDCA cycle as the phases of AR. This can cause particular confusion, since the PDCA is not an AR technique applied to quality issues. In fact, AR is a contrary idea to the predetermination of thinking and an acting cycle and it has a participative, questioning and critical openness (Thiollent, 2009).

Another concern when analyzing phases or cyclic processes is the fact that not all articles demonstrated concern about either the evaluation of the results or the obtained learning, presenting only the reasons why such 'strategy' had been chosen, but nothing about the changes resulting from them. This is an important factor because by the description of the phases, one can find those responsible for each of them, as well as the goals to be achieved with each type of data collection used in each of the respective phases. Once again, it is important to emphasize that this description, which does not belong to the official stages earlier presented in this article by scholars on AR, brings greater concern about the non-compliance with the theoretical framework of AR. This does not mean that adjustments may not occur.

\subsection{Results obtained from the use of action research}

The node 'results' and the sub-nodes 'knowledge generated by the use of AR.' and 'difficulties encountered by the use of AR.' were created. From this, the current study aimed to achieve answer to the following questions: "what knowledge is obtained when using action research? Is it different from other research methods?"

Coding was carried out in the main node 'results'. This coding refers to the practical results obtained regarding the application of AR. About this, there is the following text fragment extracted from the analyzed articles.

QFD proved to be an efficient method of research and development of production processes. The methodology enabled the interaction among different areas of work and, as the end result, an excellent diagnosis of the qualitative conditions of the manufacturing processes was obtained [...] (Wagner \& Godoy, 2004).
An aspect to be emphasized and that was noticed is that researchers are very concerned to present the practical results that can be and are obtained through the use of AR, as a result of being mostly positive for institutions or companies where the respective researches were carried out, however, the knowledge acquired for having used such a method was not detailed reported.

\subsubsection{Knowledge generated by the use of action research}

The sub-node "knowledge generated by the use of AR' was created. After that, a comparison between the sub-node 'knowledge generated by the use of AR' and the node 'goal of AR' was carried out.

The following excerpt shows the results directly linked to the possible knowledge impacting people and production processes.

Other results obtained: greater knowledge of production teams (operation and supervision) on the impact of the process on the final quality of the product; knowledge of application of whitewash and its functions within the steelmaking process; several intangible types of knowledge were explained and aggregated to the operating standards; internal satisfaction of the factory professionals with the product quality and the success of the project; and replication of the project to other company products [...] (Melo Filho \& Cheng, 2004).

Therefore, this quotation reminds us of knowledge generated through the actions that brought technical contribution to both the organization and the production teams.

When reading the codes, there is certain frequency with respect to the contribution linked to the term participation. However, the collective action that guides the changes resulting from participation motivated by the presence of all members ends up not being highlighted by the articles. This fact is a bit astonishing, since participation is the motivating center of the use of AR, and thus, it would be reasonable to find similar results and consistent with it.

As a result, a new question arises: about the difficulties reported by the authors. This issue is addressed in the next section.

\subsubsection{Difficulties obtained by using action research}

"What difficulties did the authors report when doing action research?" The sub-node "difficulties to use AR' was created, and then fifteen articles explicitly stating those difficulties were identified. 
The difficulties are mostly related to the project's execution time and its cost. This is because researchers have to meet the funding agencies' requirements, meeting their deadlines, which are different from the companies and/or the institutions. This may become a complicating factor to the development of an AR project. Another aspect that may threaten a project is the difficulty related to the involvement of people interested in it, since it is necessary to conciliate differences and personal divergences. In this case, the experience of the researcher as a mediator will be fundamental to go through this difficulty.

\section{Conclusion}

The reasons that lead national researchers to adopt AR in their research are the themes participation and intervention. However, this participation must be further exploited by the community, since the participatory process is much more global and comprehensive, and thus cooperative. Promoting intervention is what AR advocates. Nevertheless, not an imposed intervention in the sense of obedience to a superior order. The intervention suggested by theory is closely linked to the process of change needed to achieve practical results, consequently contributing to academic knowledge. There is a gap, then, among the reasons that motivate PE researchers to choose AR. Another very important aspect to consider is the relation that the national researcher establishes between AR and the practical work that can be developed. What draws attention is that many authors focus only on practical problems solving, forgetting important aspects of AR, which are essential for a better implementation of it, such as explicitly presenting the results obtained from the use of AR. In other words, present how AR contributed to the enrichment of knowledge in the area. In this respect, the use that PE makes of AR is the one with practical purposes, as presented in item 2.2, not exploiting the potential of collective actions carried out for the construction of new knowledge.

In relation to the cyclical processes, one can affirm that the Brazilian PE aims at a flexibility of research according to the subarea of the PE to meet its objectives and interests. Thus, it makes adjustments to the cyclical process models for its development. Certainly, what can be considered even more aggravating is the fact that these articles do not report the research conduct process, not describing how AR can effectively contribute to the research project carried out. Therefore, once again the PE has a practical overview, focused on results that meet the company's needs. Perhaps this result is linked to the specific characteristics of the PE itself.
As a result, initially there was a claim to develop a model or a manual to those production engineers interested in doing AR in order to help them in their research. Later, this claim was abandoned, thanks to the diversity in the PE area, as well as AR itself. It is extremely difficult to build a model of stages or rules for researchers to follow - also called research conduct process or research protocol - what was later found unnecessary throughout the research. It would be just another one among many others in literature - either national or international. ls that what the Brazilian PE needs to use AR as promoted by the literature?

The sure answer is no. The practice of AR requires the researcher to realize that this is an option for achieving results which would not be possible to obtain from other methods. This does not mean that the knowledge obtained from this method lacks values, considering them ethical and moral values.

Thus, it is important to point out that the result obtained from the use of AR is different from the result achieved when using another method of scientific research. Considering the fact that in scientific research where the researcher applies questionnaires and / or obtains his results unilaterally, already leads us to believe that this result has a bias, which can be a closer look at the researcher, or even of the company where the research was conducted. When using AR, the process of learning is present in such a way that participation is the foundation of this vast experience's growth. It is hard to imagine that the results would be the same. What cannot be stated in general terms is whether the result is better when using AR or not. However, from the present study, it is possible to affirm that Brazilian PE does not perform AR as recommended by theory. But this does not mean that its use is the result of a fad or an unqualified use of its theoretical basis. There is actually more interest in using $A R$, since other methods are not able to generate the results obtained from AR.

Thus, it is important to highlight that this article was designed in eagerness to demystify the practice of AR, of its principles and its objectives, believing that if linked to more participatory and democratic business projects, qualified AR can be carried out successfully for both the academy and companies in general.

For future studies, we suggest as database articles published in this journal and others of the same national relevance, using the same categories presented here, as well as the use of content analysis and $\mathrm{NVivo}^{\circledR}$ software. Then, carry out a comparison of the results, and thus, with this wider scope regarding studies conducted in Brazil, point out trends of better practices and uses of AR. 


\section{References}

Associação Brasileira de Engenharia de Produção - ABEPRO. (2013). Anais da Associação Brasileira de Engenharia de Produção. Rio de Janeiro: ABEPRO. Retrieved in 27 February 2013, from http://www.abepro.org.br/publicacoes

Bardin, L. (2011). Análise de conteúdo. São Paulo: Edições 70.

Baskerville, R. (1999). Investigating Information Systems with action research. Communications of the Association for Information Systems, 2(19), 2-31. Retrieved in 27 February 2013, from http://dl.acm.org/

Cota Junior, M. B. G., \& Cheng, L. C. (2006). Aplicação do QFD e do PCP a Produtos Digitais. In Anais Encontro Nacional de Engenharia de Produção, Fortaleza.

Coughlan, P., \& Coghlan, D. (2002). Action research for operations management. International Journal of Operations \& Production Management, 22(2), 220-240. http://dx.doi. org/10.1108/01443570210417515.

Desroche, H. (1981). La recherche coopérative comme rechercheaction. In Actes du Colleque sur la Recherché-action, Chicoutimi.

Desroche, H. (2006). Pesquisa-ação: dos projetos de autores aos projetos de atores e vice-versa. In M. Thiollent (Ed.), Pesquisa-ação e projeto cooperativo na perspectiva de Henri Desroche. São Carlos: EdUFScar.

Dick, B., Stringer, E., \& Huxham, C. (2009). Theory in action research. Action Research, 7(1), 5-12. http://dx.doi. org/10.1177/1476750308099594.

Dionne, H. (2007). A pesquisa-ação para o desenvolvimento local. Brasília: Liber Livro.

Dubost, J. (1987). L'intervention psycho-sociologique. Paris: PUF.

Dubost, J., \& Levy, A. (2002). Recherche-action et intervention. In J. Barus-Michel, E. Enriquez \& A. Levy (Eds.), Vocabulaire de psychosociologie. Ramonville: Erès.

Eden, C., \& Huxham, C. (2000). Pesquisa-ação no estudo das organizações. In S. R. Clegg, C. Hardy \& W. R. Nord (Eds.), Handbook de Estudos Organizacionais (Vol. 2). São Paulo: Atlas.

El Andaloussi, K. (2004). Pesquisas-ações: ciências: desenvolvimento: democracia. São Carlos: EdUFScar.

Franco, M. A. S. (2005). Pedagogia da pesquisa-ação. Educação e Pesquisa, 31(3), 483-502. http://dx.doi.org/10.1590/ S1517-97022005000300011.

Godoy, A. S. (1995). Pesquisa qualitativa: tipos fundamentais. Revista de Administração de Empresas, 35(3), 20-29. http://dx.doi.org/10.1590/S0034-75901995000300004.

Gustavsen, B. (2003). New forms of knowledge production and the role of action research. Action Research, 1(2), 153-164. http://dx.doi.org/10.1177/14767503030012003.
Huxham, C., \& Vangen, S. (2003). Researching organizational practice through action research: case studies and design choices. Organizational Research Methods, 6(3), 383-403. http://dx.doi.org/10.1177/1094428103254454.

Lewin, K. (1951). Field theory in social science; selected theoretical papers. New York: Harper \& Row.

Liu, M. (1997). Fondements et pratiques de la recherche action. Paris: L'Harmattan.

Melo Filho, L. D. R., \& Cheng, L. C. (2004). Aplicação do método QFD em uma indústria de materiais. In Anais Encontro Nacional de Engenharia de Produção, Florianópolis.

Morin, A. (2004). Pesquisa-ação integral e sistêmica: uma antropopedagogia renovada. Rio de Janeiro: DP\&A.

O’Brien, R. (1998). An overview of the methodological approach of action research. Toronto: University of Toronto. Retrieved in 27 February 2013, from http://www.web.net/ robrien/ papers/arfinal.html\#_Toc26184662

Oliveira, D. T., Cortimiglia, M. N., \& Fogliatto, F. S. (2008). Aplicação de pesquisa-ação na operacionalização da gestão do conhecimento em ambientes virtuais de aprendizagem à distância. In Anais Encontro Nacional de Engenharia de Produção, Rio de Janeiro.

Reason, P., \& Bradbury, H. (2001). Handbook of action research: participative inquiry \& practice. London: Sage Publications.

Reason, P., \& McArdle, K. L. (2003). Action research and organization development. In S. Becker \& A. Bryman (Eds.), Understanding research methods for social policy and practice. London: Sage Publications.

Susman, G. 1., \& Evered, R. D. (1978). An assessment of the Scientific Merits of Action Research. Administrative Science Quarterly, 23(4), 582-603. http://dx.doi.org/10.2307/2392581.

Thiollent, M. (2009). Pesquisa-ação nas organizações. São Paulo: Atlas.

Thiollent, M. (2011). Metodologia da Pesquisa-ação. São Paulo: Cortez.

Turrioni, J. B., \& Mello, C. H. P. (2010). Pesquisa-ação na Engenharia de Produção. In P. A. C. Miguel (Ed.), Metodologia de pesquisa em engenharia de produção e gestão de operações. Rio de Janeiro: Elsevier.

Wagner, A., \& Godoy, L. P. (2004). Desenvolvimento da qualidade nos processos de produção: uma investigação pelo método QFD. In Anais Encontro Nacional de Engenharia de Produção, Florianópolis.

Westbrook, R. (1995). Action Research: a new paradigm for research in production and operations management. International Journal of Operations \& Production Management, 15(12), 6-20. http://dx.doi.org/10.1108/01443579510104466. 